\title{
Patient compliance in a clinical trial with inhaled budesonide in children with mild asthma
}

\author{
G. Jónasson*, K-H. Carlsen**, A. Sødal*, C. Jonasson" ${ }^{\#}$ P. Mowinckel ${ }^{\#}$
}

Patient compliance in a clinical trial with twice daily inhaled budesonide in children with mild asthma. G. Jónasson, K-H. Carlsen, A. Sødal, C. Jonasson, P. Mowinckel. (C)ERS Journals Ltd 1999.

ABSTRACT: Children's use of inhalation devices can give valuable information about their adherence to asthma therapy. The aim of this study was to examine treatment adherence of low dose inhaled budesonide or placebo administered via Turbuhaler $\mathbb{R}$ twice daily in children with mild asthma participating in an asthma trial, by comparing diary registration with the number of doses remaining in the inhaler.

A total of 163 children (age 7-16 yrs, 56 females, 107 males) with mild asthma (mean baseline forced expiratory volume in one second (FEV1) was $103 \%$ of predicted), were included into a double blind, randomized study. After a two-week run-in period, the children received inhaled budesonide, either $100 \mu \mathrm{g}$ or $200 \mu \mathrm{g}$ daily, and/or placebo for 12 weeks. All patients used daily diary cards throughout the study.

Results from 161 patients were analysed. Mean compliance according to the diary was $93 \%$, whereas estimated mean compliance when counting remaining doses in the Turbuhaler was $77 \%$. Overuse of medication was found in $7 \%$ of the children. There was no significant difference in compliance between sex in the study group, whereas children aged $\leq 9$ yrs had significantly better drug adherence than older children. No significant relationship was found between symptom score and compliance.

In conclusion, even with optimal patient follow-up in a clinical trial, adherence to prophylactic asthma treatment is considerably lower than the patients own reports from the use of daily diary cards.

Eur Respir J 1999; 14: 150-154.
*Paediatric Section for Allergy and Pulmonology, Ullevål Hospital, Oslo, Norway. **Voksentoppen, Institute of Allergy and Asthma in Children, Oslo, Norway. ${ }^{\text {Clini- }}$ cal Research and Development, Astra Norge AS, Oslo, Norway.

\section{Correspondence: G. Jónasson}

Pediatric Section for Allergy and Pulmonology

Ullevål Hospital

0407 Oslo

Norway

Fax: 4722118663

Keywords: Childhood asthma drug adherence

inhaled corticosteroids

patient compliance

Received: July 61998

Accepted after revision February 151999
Long-term studies of children with asthma have concluded that early intervention may prevent the development of irreversible airway obstruction $[1,2]$. This may influence current treatment recommendations by possibly leading to the earlier prescription of prophylactic antiinflammatory treatments in mild disease.

Some compliance studies have focused on objective measurements regarding the use of inhaled asthma medication in adults and children. This has been performed using an electronic inhaler timer device (Nebulizer Chronolog; Forefront Technologies Inc., Lakewood, CO, USA), and has repeatedly shown that adherence to asthma medication is generally poor. These studies show that only about $50-77 \%$ of the medication is used as prescribed by the doctor [3-6], and that when asked, patients overestimate the use of their own medication $50-90 \%$ of the time $[3,7,8]$. Poor compliance with prescribed therapy can lead to difficulties in assessing disease severity as the expected effect of the treatment given is missing, which may in fact influence the clinician in changing to a different, and sometimes a more complicated treatment regimen instead of focusing on improving the patient compliance. Prescribing prophylactic long-term therapy in mildly affected or asymptomatic children with asthma can possibly result in a further decline in treatment adherence.

The primary objective of the present study was to examine treatment adherence of mildly affected asthmatic children in a clinical trial, only including study subjects who were considered to be adherent to therapy. Differences between diary registrations and calculated compliance (by counting the remaining doses in the inhaler) were assessed. Secondary objectives were to evaluate the possible effect of symptom score on compliance and to compare compliance between different age groups and sex.

\section{Patients and methods}

\section{Patients}

A total of 163 children with a history of asthma were included in the study, 107 males and 56 females, aged 716 yrs. All subjects participated in a study on the effect of low dose inhaled budesonide on mild asthma, mild being defined as low grade symptoms that did not interfere with sleep and lifestyle, or episodes of cough and wheeze occurring less than once per month [9].

\section{Study design}

Treatment results and study design have been reported elsewhere [10]. The study was designed as a double-blind, randomized single-centre trial. A two-week open run-in 
period, during which the children learned to use an empty Turbuhaler $\mathrm{R}$ (Astra Draco, Lund, Sweden) for practice, a peak flow meter (Vitalograph, Ennis, Ireland) and to complete a diary, was followed by a 12-week doubleblind treatment period. At the second visit, patients were randomized into four different treatment groups, and each patient received two Turbuhalers, one for morning medication or placebo (lactose) and the other for evening medication or placebo. Patients in Group I were given budesonide $100 \mu \mathrm{g}$ once daily (in the morning and placebo $100 \mu \mathrm{g}$ in the evening). Group II received budesonide $200 \mu \mathrm{g}$ once daily (in the morning and placebo 100 $\mu \mathrm{g}$ in the evening). Group III received budesonide $100 \mu \mathrm{g}$ twice daily (morning and evening, total dose of $200 \mu \mathrm{g}$ ). The final group (Group IV) received placebo $100 \mu \mathrm{g}$ twice daily (morning and evening). Patients recorded daytime and night-time asthma symptoms in the diary on a severity scale of $0-3(0=$ no symptoms, $3=$ severe symptoms). Subjects also kept a daily record of their use of $\beta_{2^{-}}$ agonists, peak expiratory flow rate (PEFR) twice daily and intake of the study medication. Clinical assessment, lung function testing and measurement of bronchial responsiveness were performed at each visit every fourweeks throughout the study. Children participating in the present trial were not informed about the counting of remaining doses in the inhaler when it was collected at the end of the study. The study was approved by the Regional Medical Ethics Committee.

\section{Assessment of compliance}

A single dose of budesonide $100 \mu \mathrm{g}$ dry powder, $200 \mu \mathrm{g}$ dry powder or placebo dry powder was prescribed for inhalation from a Turbuhaler twice daily, i.e. morning and evening for 12 weeks. All Turbuhalers contained 200 doses at the start of the study. A proper inhalation technique with the Turbuhaler was ensured before including the patient in the study, after the run-in period and at four week intervals during the study. For this purpose, a Turbuhaler Usage Trainer (Astra Draco) was used.

When a patient uses the inhaler, the Turbuhaler grip is turned clockwise and then anti-clockwise until a "click" sound is heard. The patient then empties their lungs and inhales deeply from the inhaler. When $\leq 20$ doses remain in the inhaler, a red line becomes visible in a dosage indicator. Adherence to the treatment regimen was estimated indirectly in two ways. Firstly, patients reported intake of medication each day for 12 weeks, and secondly, the remaining doses of budesonide or placebo in the returned Turbuhaler were counted. Compliance was calculated as:

$$
\% \text { Compliance }=\frac{200-\text { No. of remaining doses } \times 100}{\text { No. of prescribed doses }}
$$

The number of doses remaining in the Turbuhaler were determined by counting the "clicks" until the red line indicator became visible. The number of "clicks" counted was then added to 20 ( 20 being the number of doses remaining in the inhaler when the red indicator is visible).

A pilot counting study was performed by counting the remaining doses in 20 unused Turbuhalers; the maximum difference from the expected 200 doses was 10 doses, or
5\%. This was also performed in a blinded way i.e. 20 unused Turbuhalers were "clicked" 30-175 times by one person and remaining doses counted by another person. The maximum difference between expected and counted doses in the Turbuhaler was measured as 10 doses or $5 \%$.

\section{Statistical evaluation}

The compliance level assessed by diary (self reported) and by counting remaining doses (measured) was compared using Student's two-sample t-test. To determine the degree of association with any demographic variables, analysis of covariance (ANCOVA) or paired t-tests were used. $p$-values $\leq 0.05$ were considered to be significant.

\section{Results}

\section{Patients}

A total of 163 patients were included in the study. At the end of the study, data on doses remaining in the inhalers and diary registrations were available from 161 patients. One patient was withdrawn from the study due to lack of compliance with no diary data available after randomization, and one patient had lost their inhalers. The demographic details of the subjects are given in table 1 .

\section{Assessing compliance}

A significant difference was found between self reported (diary cards) and measured compliance for both morning and evening medication (table 2). When comparing mean values of compliance between morning and evening medication, the latter was slightly higher for both diary and measured compliance, but this difference was not significant.

Ninety-four (58\%) patients obtained $\geq 75 \%$ measured compliance for morning medication versus 108 (67\%) patients for evening medication. In these major groups of patients, a statistically significant difference between diary registrations and measured compliance $(\mathrm{p}=0.007 ; \mathrm{p}<0.001$, respectively) was found (table 3 ). This difference between

Table 1. - Personal and lung function data at baseline for all patients treated

\begin{tabular}{|c|c|}
\hline Characteristic & Value \\
\hline Patients $n$ & 163 \\
\hline Atopics n & 110 \\
\hline Male/Female & $107 / 56$ \\
\hline Age yrs & $9.9(7-16)$ \\
\hline Height $\mathrm{cm}$ & $143.4(118.3-202)$ \\
\hline FEV $1 \%$ of predicted $\mathrm{L} \cdot \mathrm{min}^{-1}$ & $102.7(71.6-141.5)$ \\
\hline PEF morning $\%$ pred $\mathrm{L} \cdot \mathrm{min}^{-1}$ & $87.1(45.1-139.2)$ \\
\hline Reversibility in FEV1 \% & $3.0(-28-20)$ \\
\hline \multicolumn{2}{|l|}{ Maximum fall in FEV1 } \\
\hline$\%$ after exercise test & $10.4(-3.3-62.5)$ \\
\hline $\begin{array}{l}\text { Number of } \beta_{2} \text {-agonist doses inhaled } \\
\text { during day }\end{array}$ & $0.49(0-9.4)$ \\
\hline
\end{tabular}

Results are given as mean values with range in parentheses. FEV1: forced expiratory volume in one second; PEF: peak expiratory flow. 
Table 2. - Comparison between self reported compliance (diary cards) and measured compliance by counting remaining doses in the inhaler device for all patients

\begin{tabular}{lccccc}
\hline Medication & $\mathrm{n}$ & $\begin{array}{c}\text { Diary } \\
\text { compliance \% }\end{array}$ & $\begin{array}{c}\text { Measured } \\
\text { compliance \% }\end{array}$ & p-value \\
\hline Morning & 161 & $93(91.7-94.3)$ & $76(72.6-80.2)$ & $<0.001$ \\
Evening & 161 & $94(92.8-95.1)$ & $77(73.9-80.7)$ & $<0.001$ \\
\hline
\end{tabular}

Results are given as mean values with $95 \%$ confidence intervals in parentheses.

self reported and observed values increased markedly as measured compliance decreased (fig. 1). Compliance was measured to be $<25 \%$ (mean value) in six children when counting the remaining doses for both morning and evening medication. Two additional children (one from each group) had either morning or evening compliance only $<25 \%$. The seven children with $<25 \%$ measured adherence for evening medication had $95 \%$ adherence (mean value) according to their diaries (table 3 ).

Only six (4\%) patients reported $\leq 75 \%$ drug adherence to morning medication in their diaries, whereas objective measurements revealed that 67 (42\%) children had $<75 \%$ adherence to morning medication and $53(33 \%)$ to evening medication. Compliance was found to be significantly higher in the younger age groups, as shown in table 4.

A total of $139(86 \%)$ patients had a higher reported selfcompliance than measured compliance for morning medication, compared to 151 (94\%) for evening medication. Of the remaining subjects with a reported compliance by diary cards lower than the measured compliance, "over-users" constituted a major group, with large discrepancies between measured and self reported values. The remaining subjects had almost equal self reported and measured values, although self reported values were slightly lower than the measured ones. Overuse of inhaled drugs for either morning or evening medication was observed in 11 $(7 \%)$ patients and in three $(2 \%)$ patients for both morning and evening medication. Males were more often "overusers" than females. Otherwise no significant difference was found between sex in the present study.

Table 3. - Comparison between measured compliance and self reported compliance (diary cards) in different compliance groups

\begin{tabular}{|c|c|c|c|c|}
\hline $\begin{array}{l}\text { Compliance } \\
\text { groups }\end{array}$ & $\mathrm{n}$ & $\begin{array}{c}\text { Measured } \\
\text { compliance \% }\end{array}$ & $\begin{array}{c}\text { Diary } \\
\text { compliance \% }\end{array}$ & $\mathrm{p}$-value \\
\hline \multicolumn{5}{|l|}{$\geq 75 \%$} \\
\hline Morning & 94 & $91(87.7-94.3)$ & $96(94.5-97.2)$ & $=0.007$ \\
\hline Evening & 108 & $88(85.6-90.6)$ & $95(94.0-96.5)$ & $<0.001$ \\
\hline \multicolumn{5}{|l|}{$50-75 \%$} \\
\hline Morning & 49 & $66(64.2-67.7)$ & 89 (86.4-91.3) & $<0.001$ \\
\hline Evening & 38 & $66(64.1-67.9)$ & $91(88.5-93.9)$ & $<0.001$ \\
\hline \multicolumn{5}{|l|}{$25-50 \%$} \\
\hline Morning & 11 & $37(32.8-41.9)$ & $90(86.2-94.2)$ & $<0.001$ \\
\hline $\begin{array}{l}\text { Evening } \\
\leq 25 \%\end{array}$ & 8 & $43(39.1-47.4)$ & 89 (81.4-96.1) & $<0.001$ \\
\hline $\begin{array}{l}\leq 25 \% \\
\text { Morning }\end{array}$ & 7 & $14(3.6-24.7)$ & $88(71.9-104.1)$ & $<0.001$ \\
\hline Evening & 7 & $12(5.4-19.2)$ & $95(90.4-99.7)$ & $<0.001$ \\
\hline
\end{tabular}

Results are given as mean values with $95 \%$ confidence intervals in parentheses.

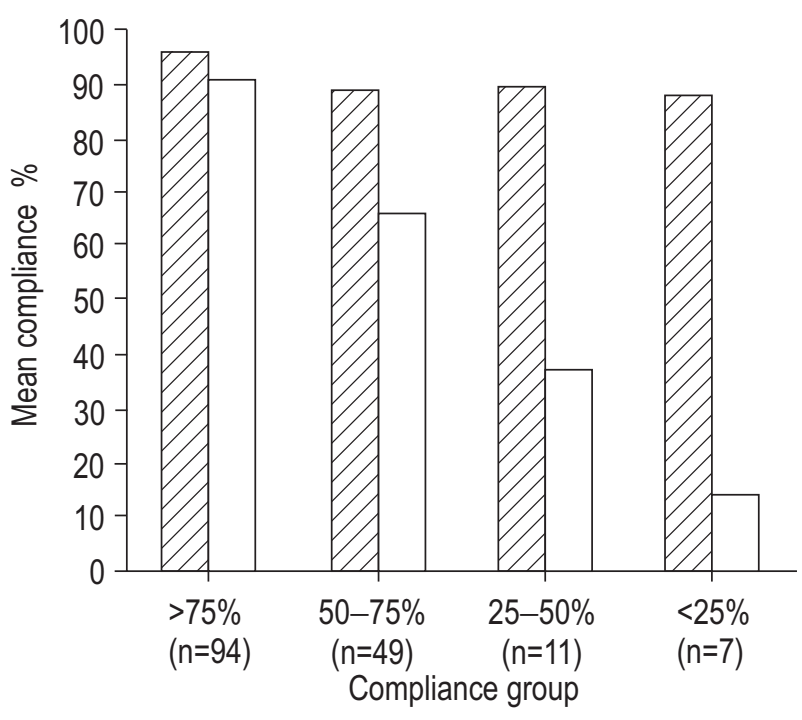

Fig. 1. - Comparison between measured $(\square)$ and self reported $(\because)$ compliance for morning medication in four different compliance groups of an asthma treatment regimen. Allocation to each group is determined by measured compliance, calculated by subtracting the number of remaining doses in the used inhaler from the number of doses in an unused inhaler and divided by the number of prescribed doses.

\section{Symptom scores and placebo treatment}

As the patients suffered from mild asthma, symptom scores were low at baseline and throughout the study for all treatment groups. At baseline, the children used a mean number of $0.49 \beta_{2}$-agonist inhalations during the day and 0.11 inhalations during the night. When comparing the compliance of symptom-free patients (daytime) to the compliance of patients with registered diary symptoms, the symptom-free group had a mean measured compliance of $75 \%$ (evening medication) whereas the diary group had a measured compliance of $79 \%$ (NS).

No significant differences between measured compliance of the placebo group and the budesonide group were found.

\section{Discussion}

In the present study, a clear discrepancy between self reported and objectively measured compliance was found. This discrepancy increased considerably as the measured

Table 4. - Comparison of measured versus diary compliance for two different age groups

\begin{tabular}{lccc}
\hline & \multicolumn{2}{c}{ Age group } & \\
\cline { 2 - 3 } Compliance & $\begin{array}{c}7-9 \text { yrs } \\
(\mathrm{n}=75)\end{array}$ & $\begin{array}{c}10-16 \text { yrs } \\
(\mathrm{n}=86)\end{array}$ & p-value \\
& & & \\
\hline Measured & & & \\
Morning \% & $81(78.1-84.7)$ & $72(65.5-78.5)$ & $=0.01$ \\
$\quad$ Evening \% & $83(80.1-86.5)$ & $72(66.6-77.7)$ & $=0.001$ \\
Diary & & & \\
Morning \% & $94(92.6-95.7)$ & $92(89.9-94.1)$ & $=0.09$ \\
Evening \% & $95(93.8-96.3)$ & $93(91.7-94.8)$ & $=0.06$ \\
\hline
\end{tabular}

Results are given as mean values with $95 \%$ confidence intervals in parentheses. 
compliance decreased. Neither symptom scores or placebo treatment significantly affected the compliance in this group of children with mild asthma. Younger children had a better compliance, possibly due to stronger parental supervision with extra motivation and help.

In the present study, the children were repeatedly encouraged and reminded to take their medication as prescribed at each visit every four weeks during the study. Inhalation techniques were checked, and possible problems regarding the treatment were discussed at all visits. Only two out of 163 children were withdrawn from the study throughout the study period.

In the present study, compliance was measured objectively by counting the number of doses remaining in the Turbuhaler. Thus, the number of doses taken by the patient was calculated. However, the timing and technique of the administration of the drugs cannot be assessed in this way. The measured compliance therefore represents the theoretical "best" compliance value.

Overuse of the inhaler was estimated indirectly in this way by counting the remaining doses and found to be $7 \%$ in the present study, but other studies have shown similar estimates of overuse of medication in trials [5]. The possibility that the actual number of remaining doses overestimates drug adherence ("clicking" the inhaler without inhaling) cannot be ruled out. This kind of overuse or "test firing" has been shown by others with the use of an electronic medication monitor in the inhaler $[5,8]$. This electronic instrument cannot confirm that the medication was inhaled or used correctly, but only when and how often the inhaler was actuated.

It has been shown that participating in a clinical trial can increase the patients motivation and compliance [11]. Only patients deemed to be compliant were selected for this trial. Although the results show that this selection was not completely successful, with 18 patients taking $<50 \%$ of their medication (fig. 1), there is little doubt that the present study overestimates compliance in relation to clinical routines, and is in that respect hardly comparable to "real" compliance in a usual clinical practice when treating asthmatic children. If this statement is true, it means that the physician responsible for prescribing the treatment should not overlook the possibility that the patient is either not using the medication as prescribed, or not using it at all. MiLGROM et al. [3] studied compliance in 24 asthmatic children over a 13-week period. They found that $>90 \%$ of the patients exaggerated their use of inhaled steroids, and the ratio of diary doses to prescribed doses was $95.4 \%$ (median value) compared to the measured compliance of $58.4 \%$ for inhaled steroids. The same group also found a striking relationship between poor steroid adherence and asthma exacerbations. The present study included only children with mild asthma, and this may explain why clear relationship between symptoms and patient compliance was not found. Otherwise, the results from the study of MiLgrom et al. [3] are comparable to the results in the present study.

GIBSON et al. [6] published a study on compliance involving 29 pre-school children with an electronic inhaler timer device. They reported that an overall median of $77 \%$ of prescribed doses of therapy were taken during the study period and no apparent relationship between good compliance and low symptoms scores. Results from the present study support this finding, and the large number of patients included may give an even more reliable estimate of the measured compliance.

An inadequate therapeutic response in the treatment of asthma is not uncommon and is often dealt with either by increasing the prescribed doses or changing the therapeutic regimen. With increasing knowledge regarding poor patient compliance, the physician should possibly focus more on this aspect when prescribing medication or evaluating the effect of the treatment given. Repeated informative discussions with the patient and/or parents about the treatment given, including both the effect and possible sideeffects, is probably important. Repeated evaluation of the inhalation technique with simple and realistic treatment regimens may also be important factors when trying to increase drug adherence. Written patient instructions regarding the intake of medication and a plan for treating disease exacerbation is also likely to result in a better compliance and thereby possibly reduce morbidity.

The present study concerns the treatment of mild asthmatic children with low dose inhaled steroids. Guidelines now recommend the use of $\beta_{2}$-agonists only as needed in the treatment of mild asthma [9, 12], but inhaled steroids have occasionally been used in the treatment of mild asthma during the last few years. In children with mild disease, the recommended dose is $50-200 \mu \mathrm{g}$ given twice daily [13].

If prophylactic anti-inflammatory treatment of mild asthma is to be used more in the years to come, this will inevitably mean treating patients with lesser symptoms. The authors speculate that this trend in the treatment of asthma will present the physician with an even greater challenge in finding methods to increase their patients' drug adherence. The authors also raise the question of whether designs of clinical trials should include some form of measurement to objectively assess patient compliance in the trial.

In the present paper, the authors have shown that there is reason to believe that patient drug adherence in a clinical trial is generally much poorer than the patient actually reports. A better understanding and acceptance of how poor patient compliance really is, is probably the key to finding ways to reduce this problem in the future.

Acknowledgements. Astra Draco, Lund, Sweden, delivered budesonide, terbutaline and placebo Turbuhalers, as well as diaries and case report forms.

\section{References}

1. Agertoft L, Pedersen S. Effects of long-term treatment with an inhaled corticosteroid on growth and pulmonary function in asthmatic children. Respir Med 1994; 88: 373-381.

2. König P, Shaffer J. The effect of drug therapy on long term outcome of childhood asthma: a possible preview of the international guidelines. J Allergy Clin Immunol 1996; 98: 1103-1111.

3. Milgrom H, Bender B, Ackerson L, Bowry P, Smith B, Rand C. Noncompliance and treatment failure in children with asthma. J Allergy Clin Immunol 1996; 98: 10511057.

4. Bosley CM, Parry DT, Cochrane GM. Patient compliance with inhaled medication: does combining beta-agonists 
with corticosteroids improve compliance. Eur Respir $J$ 1994; 7: 504-509.

5. Coutts JAP, Gibson NA, Paton JY. Measuring compliance with inhaled medication in asthma. Arch Dis Child 1991; 67: 332-333.

6. Gibson NA, Ferguson AE, Aitchison TC, Paton JY. Compliance with inhaled asthma medication in preschool children. Thorax 1995; 50: 1274-1279.

7. Spector SL, Kinsman R, Mawhinney H, et al. Compliance of patients with asthma with an experimental aerosolized medication: implications for controlled clinical trials. J Allergy Clin Immunol 1986; 77: 65-70.

8. Rand CS, Wise RA, Nides M, et al. Metered-dose inhaler adherence in a clinical trial. Am Rev Respir Dis 1992; 146: $1559-1564$.
9. Warner JO, Neijens HJ, Landau LI, et al. Asthma: a follow up statement from an international paediatric asthma consensus group. Arch Dis Child 1992; 67: 240248.

10. Jónasson G, Carlsen K-H, Blomqvist P. Clinical efficacy of low dose inhaled budesonide once or twice daily in children with mild asthma not previously treated with steroids. Eur Respir J 1998; 12: 1099-1104.

11. Reiser J, Warner JO. The value of participating in an asthma trial. Lancet 1985; 26: 206-207.

12. Sheffer AL, Bousquet J, Busse WW, et al. International consensus report on diagnosis and treatment of asthma. Eur Respir J 1992; 5: 601-641.

13. Woodhead M. Guidelines on the management of asthma. Thorax 1993; 48: S1-S26. 